\title{
Evaluation of the Relative Importance of Parameters Influencing Perforation Cleanup
}

R.L. Detwiler, J.P. Morris, C.O. Karacan, P.M. Halleck, and J.T. Hardesty

This article was submitted for presentation at the SPE International Symposium and Exhibition on Formation Damage Control held in Lafayette, Louisiana, U.S.A., 18-20 February 2004.

U.S. Department of Enargy

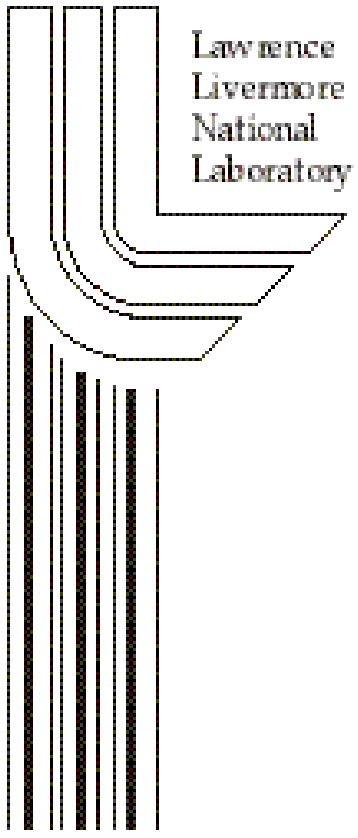

October, 2003 


\section{DISCLAIMER}

This document was prepared as an account of work sponsored by an agency of the United States Government. Neither the United States Government nor the University of California nor any of their employees, makes any warranty, express or implied, or assumes any legal liability or responsibility for the accuracy, completeness, or usefulness of any information, apparatus, product, or process disclosed, or represents that its use would not infringe privately owned rights. Reference herein to any specific commercial product, process, or service by trade name, trademark, manufacturer, or otherwise, does not necessarily constitute or imply its endorsement, recommendation, or favoring by the United States Government or the University of California. The views and opinions of authors expressed herein do not necessarily state or reflect those of the United States Government or the University of California, and shall not be used for advertising or product endorsement purposes.

This is a preprint of a paper intended for publication in a journal or proceedings. Since changes may be made before publication, this preprint is made available with the understanding that it will not be cited or reproduced without the permission of the authors. 


\section{Evaluation of the Relative Importance of Parameters Influencing Perforation Cleanup}

Russell L. Detwiler and Joseph P. Morris, Lawrence Livermore National Laboratory; C. Ozgen Karacan and Phillip M.

Halleck, Penn State University; John Hardesty, Jet Research Center

\begin{abstract}
Completion of cased and cemented wells by shaped-charge perforation results in damage to the formation, which can significantly reduce well productivity. Typically, underbalanced conditions are imposed during perforation in an effort to remove damaged rock and shaped-charge debris from the perforation tunnel. Immediately after the shaped-charge jet penetrates the formation, there is a transient surge of fluid from the formation through the perforation and into the well bore. Experimental evidence suggests that it is this transient pressure surge that leads to the removal of damaged rock and charge debris leaving an open perforation tunnel.

We have developed a two-stage computational model to simulate the perforation process and subsequent pressure surge and debris removal. The first stage of the model couples a hydrocode with a model of stress-induced permeability evolution to calculate damage to the formation and the resulting permeability field. The second stage simulates the non-Darcy, transient fluid flow from the formation and removes damaged rock and charge debris from the perforation tunnel. We compare the model to a series of API RP43 section 4 flow tests and explore the influence of fluid viscosity and rock strength on the final perforation geometry and permeability.
\end{abstract}

\section{Introduction}

Shaped-charge perforation is often used to complete cased wells. Detonation of a shaped-charge creates a high-velocity $(\sim 7000 \mathrm{~m} / \mathrm{s})$ jet of metal particles that penetrates the well casing and the adjacent formation. The jet leaves a path of debris consisting of crushed rock and metallic particles while generating a shock wave that propagates outward through the formation. The shock wave damages rock surrounding the perforation, resulting in a region with altered permeability. ${ }^{1,2}$ Typically, prior to shaped-charge detonation, the wellbore pressure is reduced to below the pore pressure in the reservoir (underbalanced) to promote a transient pressure surge and high velocity flow through the perforation and adjacent region of the formation. The underbalance-induced surge results in partial removal of debris and damaged rock from the perforation, leaving an open tunnel surrounded by a zone of damaged rock. Experimental results suggest that this removal of debris and damaged rock occurs on a time-scale of milliseconds. $^{3}$

A variety of models have been proposed to simulate different stages of the perforation process and provide estimates of the post perforation permeability of the damaged zone. Pearson and Zazovsky ${ }^{4}$ developed a model of the transport of sand grains through the perforation tunnel to the well bore to demonstrate the minimum underbalance required to remove debris from the perforation tunnel. Arora and Sharma ${ }^{4}$ modeled the migration of fines within the formation and calculated their influence on the post-perforation permeability of the damaged zone. Additional efforts have aimed at understanding the three-dimensional flow geometry near perforations under downhole conditions. ${ }^{5,6}$. While these models address different aspects of the perforating process. they all assume an initial perforation tunnel geometry and permeability distribution within the surrounding rock. We present a model that explicitly calculates both the permeability distribution and the final post surge geometry of the perforation tunnel in Berea sandstone. Our model consists of two sequential stages: 1) jet penetration of the casing and rock formation and 2) underbalanced-induced pressure surge and debris removal. We compare measured perforation tunnel geometries and core-flow efficiencies (CFEs) for a series of API RP43 section 4 flow tests in Berea sandstone cores to simulated estimates for the same underbalance conditions.

\section{Model Description}

We have developed a two-stage perforation model to investigate the relative importance of the parameters that influence perforation tunnel geometry and the final permeability distribution surrounding the perforation tunnel. The first stage couples a hydrocode used to simulate mechanical deformation of the rock caused by the shapedcharge jet with a model of stress-induced alteration of the rock permeability. This model thus provides a detailed map of the permeability distribution in the formation prior to the onset of flow from the formation that is based upon independently measured rock properties. The second stage solves for the transient flow of fluid from the formation and the resulting removal of damaged rock from the perforation tunnel. Because the time scale of the jet penetration and shock wave propagation is considerably smaller than the time scale for equilibration of post-perforation fluid pressures, these processes are simulated sequentially. Furthermore, the models assume radial symmetry and thus solve the problems in two dimensions (Fig. 1).

Hydrocodes used to simulate shaped-charge perforations can provide estimates of the extent of the damaged zone, but do not typically provide estimates of the post-perforation permeability distribution within the damaged formation. Morris et al. ${ }^{7}$ presented a model for predicting the evolution of the porosity and permeability of Berea sandstone undergoing low-strain-rate deformation. We modify their model to accommodate the high-strain-rate conditions encountered during jet perforating and incorporate this modified porositypermeability model into a hydrocode used to simulate jet penetration. ${ }^{8}$

Morris et al. used an elastic-plastic material model. ${ }^{8,9}$ to determine the stress-strain response of Berea sandstone and quantified the total porosity as the sum of incipient porosity and dilatant porosity. They assumed that changes in permeability result only from alterations in the incipient porosity (see Appendix A for details). The model demonstrated good agreement with low-strain-rate experimental measurements presented by Zhu and Wong. ${ }^{10}$

To extend this approach to the high-strain-rate conditions that occur during jet perforating we assume the fluid does not have time to flow in response to porosity changes. Thus, the fluid is confined within individual pores and local fluid pressure responds to changes in pore volume. This limit may be thought of as corresponding to an undrained experiment. 
An increase in pore pressure results in a reduction in the effective stress and consequently the apparent confinement and strength of the rock is reduced. This high strain rate approach is presented in Morris et al. ${ }^{11}$

Morris et al. ${ }^{7}$ assumed that although the dilatant porosity may be connected it does not make a substantial contribution to flow. This is consistent with the dilatant porosity having poor connectivity or higher surface area to volume ratio. Using this approximation, the experimentally measured porosity is the sum of the surviving incipient porosity and induced dilatant porosity. However, only the incipient porosity contributes to flow, resulting in a model for permeability that is related to incipient porosity, effective stress history, and a damage variable (see Eq. A12). Due to the lack of experimental data regarding stress-induced permeability alteration in anisotropic media, the current model assumes an isotropic permeability field.

Fig. 2 shows an example of the permeability field that results from simulating jet penetration of a core of Berea sandstone. The permeability of the debris in the damaged zone is reduced by several orders of magnitude. However, this material has also been considerably weakened due to grain fragmentation, and will likely be removed from the perforation tunnel during the post-perforation pressure surge.

Upon penetration of the formation, underbalance causes a transient expansion of the higher-pressure fluid in the formation and flow towards the opening created in the well casing by the jet. This results in large pressure gradients immediately after perforation in which inertial forces likely play a significant role. ${ }^{12,13}$. We solve for the transient pressure distribution within the formation using

$$
\square^{2} P=\frac{\square_{f} \square}{k} \frac{\partial P}{\partial t}
$$

which assumes a slightly compressible fluid where $\square_{f}$ is the fluid compressibility $\square$ is the dynamic viscosity, $\square$ is the porosity and $k$ is the local permeability. Because inertial terms may be important, especially at early times, we use the Forchheimer equation,

$$
\square \square P=\frac{1}{\square}\left|\frac{\square}{\mid}+\square\right| \vec{u} \mid \overrightarrow{\mid l},
$$

to represent $P$ in solving (1) for the pressure distribution, where $\square$ is the fluid density and $\mathrm{B}=1.1116 \times 10^{-12} / k^{1.55}$ is the empirically derived coefficient of inertial resistance, ${ }^{13}$ which accounts for the increasing importance of inertial forces at higher fluid velocities. At low fluid velocities, (2) reduces to Darcy's equation. We use a centered-in-space, backward-intime finite difference scheme to solve (1) during the postperforation surge. Adaptive time stepping ensures small changes in $P$ and $k$ between time steps.

Removal of damaged rock from the tunnel walls occurs during the initial pressure surge and is determined locally by the magnitude of the pressure gradient within each grid block. The threshold for removing damaged rock is a combination of the tensile and shear strength of the damaged rock. We assume that the tensile strength of the rock surrounding the perforation is considerably smaller than the shear strength. Thus, if in any time-step the local pressure gradient exceeds the critical value, ${ }^{4}$

$$
\square P_{c r}=\frac{\square_{t}}{2 a},
$$

we assume that the damaged rock in that grid block is loosened from the wall and eventually swept from the perforation tunnel. This assumes that once material is loosened from the tunnel wall, there is adequate flow velocity in the perforation tunnel to carry the debris to the wellbore, or if not, that the permeability of the loose debris is sufficiently high that it does not significantly impede flow through the perforation tunnel. $\square_{t}$ is the tensile strength of the rock and $a$ is a characteristic grain diameter of the rock along the tunnel wall, which we estimated to be $0.1 \mathrm{~mm}$ for the simulations presented in this paper.

The plastic strain experienced by a material element during the hydrocode simulation provides an indication of the damage sustained by that element. We relate the local tensile strength of the rock, $\square_{t}$, to the plastic strain $\left(\square_{p}\right)$ that the rock was subjected to during jet penetration,

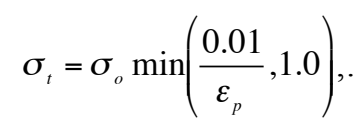

where $\square_{o}$ is a reference value for undamaged rock. We use a value of $0.01 \mathrm{GPa}$ for the simulations in Berea sandstone presented in this paper. Once $\square P_{c r}$ is exceeded, solids are removed from the element over a time scale of $\square x /|v|$ and $k$ increases linearly from $k_{o}$ to $k_{\max }$. Fig. 3 shows the evolution of permeability and pressures within the simulated core during the post-perforation pressure surge.

Initially the fluid in the reservoir is at a uniform pressure and the perforation tunnel is completely filled with damaged rock and charge debris. Flow is then initiated by setting the well bore pressure to the desired underbalance ( $750 \mathrm{psi}$ for this example). Debris is removed axially along the length of the tunnel until local pressure gradients are insufficient to overcome the required yield stress. At steady-state there is a slightly wider damaged zone near the well bore which results in substantially larger pressure gradients near the tunnel entrance. Conversely, the tip half of the tunnel has a thinner damaged zone but smaller pressure gradients.

We calculated local mass fluxes to investigate the influence of axial variability in the extent of the damaged zone and the magnitude of pressure gradients on flow to the perforation tunnel. Fig. 4 shows steady-state mass flux in the region surrounding the perforation tunnel for perforations at 750-psi and 3000-psi underbalance. For the 750-psi case, the large damaged zone observed in Fig. 3 remains intact and impedes flow into the tunnel near the entrance despite larger pressure gradients in this region relative to the tip. Conversely, the additional removal of damaged rock from near the entrance at 3000-psi underbalance results in larger mass fluxes near the tunnel entrance than near the perforation tip. This change in flow regime from low to high underbalance is in part due to the pressure boundary conditions applied during the simulations. As with API RP43 section 4 flow tests, we prescribe uniform constant pressure boundary conditions along the length of the core. Thus, underbalances that are sufficiently high to remove the damaged rock surrounding the tunnel entrance result in larger pressure gradients and more flow in this region. However, under downhole conditions, the 
presence of multiple perforations and the three-dimensional geometry of the flow field will result in a pressure field that favors flow to the perforation tip. ${ }^{5,6}$ This suggests that enhanced CFEs observed at high underbalance may exaggerate the actual productivity of perforations under field conditions.

\section{Comparison of Computational and Experimental Results}

We test the two stages of our model through comparisons with results from a series of API RP43 section 4 flow tests on cores of Berea sandstone at underbalances ranging from 750 psi to 3000 psi. The $0.178 \times 0.394 \mathrm{~m}(7 \times 15.5 \mathrm{in})$ cores were cut perpendicular to the bedding planes resulting in axial permeabilities of $\sim 125 \mathrm{mD}$ and cross diameter permeabilities of $\sim 55 \mathrm{mD}$. These tests provide a bulk measurement of the change in permeability of the core resulting from perforation. After completion of the flow tests, the cores were scanned using high-resolution x-ray CT techniques. ${ }^{15}$. This provided detailed three-dimensional images of the geometry of the perforation tunnels and the locations of any remaining charge debris within the perforation tunnels. Fig. 5 compares open tunnel radius plotted against tunnel length for the experiments and simulations. The simulated perforation tunnels exhibit similar characteristics to the experimentally measured tunnels: they decrease in radius towards the tip and larger underbalance results in larger tunnel radii, particularly near the well bore. The radii of the simulated perforation exhibit a stronger dependence on underbalance than the experiments. This may in part be due to the form of Eq. 4, which has not been independently verified. In addition, the radii of the simulated tunnels vary more smoothly than the experiments, which may be due to layering in the rocks resulting in local variability in $\square_{t}$ and $k$ that are not represented in the model. Though there are discrepancies between the simulations and experiments, it is encouraging that a model largely based upon independently measured rock properties can provide reasonable predictions of physical experiments.

To further evaluate the capability of the simulations to predict experimental observations, we compare the CFEs calculated for the experiments to the simulated CFEs (Fig. 6). CFE is calculated as the ratio of the permeability of the perforated core to the permeability of a core with the same perforation tunnel geometry with no damage (i.e. $k=k_{o}$ ). For medium to high underbalances, the simulations predict CFE values reasonably well, but at low underbalance, the simulated CFEs significantly underestimate experimental values. This may result from the nature of debris filling the tunnel. X-ray CT scans of the tunnels show metal charge debris plugging the tip of the perforation tunnel in each of the experiments ${ }^{15}$. The remaining volume of metal decreases with increasing underbalance, however, for the 750-psi underbalance core, there was an annulus surrounding the metal plug through which fluid can enter the tunnel. This flow conduit, which was not observed at higher underbalances, may be the cause of the large measured CFE for the 750-psi experiment. While the hydrocode tracks different material during the perforation process, the permeability and rock strength models do not differentiate between damaged rock and metal charge debris. Thus. the simulations cannot renlicate the variable influence of the metal debris at the tip of the perforation tunnel. Enhancement of the computational model to incorporate models for both materials (damaged rock and metallic charge debris) may help to gain new insights on the influence on CFEs of metal plugging the perforation tip.

To explore the role of fluid and rock properties on postperforation tunnel geometry and CFE we conducted a series of simulations in which we varied the tensile strength of undamaged rock and the fluid viscosity. Fig. 7 shows CFEs measured for simulations in which we doubled and halved the values of $\square_{o}$ and $\square$ used for the base simulations presented in Fig.6. Values of $\square_{0}$ and the details of the model chosen to represent rock strength surrounding the perforation tunnel strongly influence calculated CFEs. At lower underbalances, doubling $\square_{o}$ results in CFEs that are less than half of those estimated for the base simulations. However, changes in viscosity, which influence the rate of dissipation of the underbalance-induced pressure gradients have a negligible influence on calculated CFEs.

\section{Conclusions}

- Creation of perforation tunnels and the subsequent clean up by underbalance-induced pressure surge in sandstone can be predicted reasonably well with a sequential model that first simulates jet penetration and permeability alteration followed by simulation of the transient nonDarcy pressure surge.

- Simulations suggest that at low underbalance, most of the flow to perforation tunnels occurs toward the tip end of the tunnel, whereas at high underbalance, flow to the perforation tunnel is greater near the tunnel entrance. Thus, high CFEs measured at large underbalance may overestimate the increased productivity of a perforation under downhole conditions.

- Small changes in tunnel radius induced by variability in rock strength may lead to small alterations in the thickness of the damaged, zone and thus, significant variability in CFE estimates.

\section{Acknowledgments}

This work was performed under the auspices of the U. S. Department of Energy by the University of California, Lawrence Livermore National Laboratory under Contract No. W-7405-Eng-48. The authors thank the management of Halliburton Energy Services, Inc. and Jet Research Center permission to publish this paper.

\section{References}

1. Papamichos, E., Vardoulakis, I., and Ouadfel, H.: Permeability reduction due to grain crushing around a perforation. Int. J. Rock Mech. Sci. \& Geomech. Abstr., 30(7):1223-1229, 1993.

2. Asadi, M. and Preston, F.W.: "Characterization of the crushedzone formed during jet perforation by qualitative scanning electron microscopy and quantitative image analysis", SPE 22812 presented at the SPE Annual Technical Conference and Exhibition, Dallas, Texas, October 6-9, 1991.

3. Bartusiak, R., Behrmann, L.A., and Halleck, P.M.: "Experimental investigation of surge flow velocity and volume needed to obtain perforation clean up", J. of Pet. Sci. Eng., 17(1997):1928. 
4..Pearson, J.R.A. and Zazovsky, A.F.: "A model for the transport of sand grains from a perforation during underbalance surge", SPE 38634 presented at SPE Annual Technical Conference and Exhibition, San Antonio, Texas, Oct. 5-8, 1997.

5. Tariq, S.M.: "Evaluation of flow characteristics of perforations including nonlinear effects with the finite-element method", SPE Production Engineering (May 1987) 104.

6. Anash, J., Proett, M.A., and Soliman, M.Y.: "Advances in well completion design: A new 3D finite-element wellbore inflow model for optimizing performance of perforated completions", SPE 73760 presented at SPE International Symposium and Exhibition on Formation Damage Control, Lafayette, Louisiana, Feb. 20-21, 2002.

7. Morris, J. P.; Lomov, I. N.; Glenn, L. A.:: “A constitutive model for stress-induced permeability and porosity evolution of Berea sandstone," J. Geophys. Res., Vol. 108, No. B10, 2485, 10.1029/2001JB000463, 18 October 2003

8. Lomov, I.N., Hiltl, M., Vorobiev, O.Y., and Glenn, L.A.. "Dynamic behavior of Berea sandstone for dry and watersaturated conditions", Int. J. Impact Eng., 26(1-10):465-474, 2001.

9. Rubin, M.B., Vorobiev, O.Y., and Glenn, L.A.: "Mechanical and numerical modeling of a porous elastic-viscoplastic material with tensile failure", Int. J. Solis and Structures, 37, 1841-1871, 2000.

10. Zhu, W. and Wong, T.-f.: "The transition from brittle faulting to cataclastic flow: Permeability evolution", J. Geophys. Res., 102(B2):3027-3041, 1997.

11. Morris, J.P., Lomov, I.N., and Glenn, L.A.: "Simulating Perforation Permeability Damage and Cleanup", SPE 71316, 2002.

12. Halleck, P.M.: "Advances in understanding perforator penetration and flow performance", SPE 27981 presented at the University of Tulsa Centennial Petroleum Engineering Symposium, Tulsa, Oklahoma, August 29-31, 1994.

13. Arora, D.S. and Sharma, M.M.: "The nature of the compacted zone around perforation tunnels", SPE 58720 presented at the International Symposium on Formation Damage Control, Lafayette, Louisiana, Feb. 23-24, 2000.

14. Halleck, P.M., Karacan, C.O., Hardesty, J., and Detwiler, R.: "Changes in perforation-induced formation damage with degree of underbalance: Comparison of sandstone and limestone formations", SPE 86541 presented at SPE International Symposium and Exhibition on Formation Damage Control, Lafayette, Louisiana, Feb. 18-20, 2004.

Tariq, S.M.: "New generalized criteria for determining the level of underbalance for obtaining clean perforations", SPE 20636 presented at SPE $65^{\text {th }}$ Annual Technical Conference and Exhibition, New Orleans, Louisiana, Sept. 23-26, 1990.

Karacan, C.O. and Halleck, P.M.: "Mapping of permeability damage around perforation tunnels", In Proceedings of ETCE/OMAE2000 Joint Conference, Energy for the New Millenium, New Orleans, Louisiana, February 14-17, 2000.

\section{Appendix A}

Here we present a summary of the relevant details of the porosity-permeability model under quasistatic deformation presented by Morris et al. ${ }^{7,11}$ The evolution of the incipient porosity, which is used to calculate permeability, is described as

$$
\square_{I}^{o}=\underbrace{\mathrm{B}_{*}+C \square_{\text {eff }}\left(\square_{I} \square\left(\square *+C P_{*}\right)\right) / P_{*} \text { for } \square_{\mathrm{eff}}<P_{*},}_{I},
$$

where,

$$
\square_{e f f}=\left(\square_{1}+\square_{2}+\square_{3}\right) / 3 \square P_{p}=P_{m} \square P_{p}
$$

The material constants, $\square_{I}, C, P_{*}$, and $\square *$ along with other values specific to Berea sandstone are provided by Morris et al. ${ }^{7}$ Large hydrostatic loads and non-hydrostatic loads can lead to grain crushing leading to additional reduction in porosity and permeability. To account for formation damage, Morris et al. ${ }^{7}$ devised an adjustment to (A1),

$$
\square_{I}^{S}=\frac{\square_{I}^{o}\left(\square_{e f f}^{\max }\right)}{1.0+D}
$$

where $D$ evolves according to

$$
\begin{aligned}
\dot{D}= & c_{1} \square_{p} \min \left(\square_{e f f}, P_{s}^{*}\right)+ \\
& c_{2} H\left(\square_{\text {eff }} \square P_{h 1}\right) H\left(P_{h 2} \square \square_{\text {eff }}\right)\langle\square \nabla\rangle
\end{aligned}
$$

where $c_{1}$ and $c_{2}$ are constants, $\square$ is the plastic strain, and $v$ is the trace of the velocity tensor (positive indicates expansion). $H$ is the Heaviside function and $[x x H(x)$. The first source term increases damage in response to plastic strain. The second term causes damage in response to reductions in volume at high hydrostatic loads and $P_{h 1}$ and $P_{h 2}$ are the lower and upper bounds on the effective mean stress for which this damage term is active. The parameters in Table A1 were found to give good agreement with experiment. ${ }^{7}$

We extend this approach to dynamic problems by representing the incipient porosity $\left(\square_{I}^{D}\right)$ as the sum of pore volume that would open under static conditions $\left(D_{I}^{S}\right)$ and pore volume that is forced open by the expanding fluid. This results in

$$
\square_{I}^{D}=\square_{I} \square \frac{\square_{e f f}}{\square_{e f f}^{\max }}\left(\square_{I} \square \square_{I}^{S}\left(\square_{e f f}^{\max }, D\right)\right) .
$$

where $\square_{\text {eff }}^{\max }$ is the maximum effective stress over the history of the material element. The form of (A5) ensures continuity between the fluid porosity during loading and unloading and causes the fluid porosity to return to the reference value when the effective mean stress is zero. The fluid porosity is then given by:

$$
\square_{I}=\square_{I}^{S,}, \text { for } \square_{e f f}>\square_{e f f}^{\max }
$$

For the dynamic case, pore pressure is not prescribed externally and we introduce an extra equation to close the system and solve for the pore pressure:

$$
P_{p}=\frac{1}{\square_{f}}\left\langle\frac{S \square_{I}}{\square_{I} J} \square 1\right\rangle
$$

where $K_{f}$ is the fluid bulk modulus, $J$ is the ratio of current and reference specific volumes of the mixture, and $S$ is a saturation parameter (assumed constant during dynamic experiments). Equation (A7) was derived assuming that the pore fluid is confined and obeys a linear equation of state. Eq. A7 refers to the fluid porosity, so $P p$ must be eliminated from (A7) and (A6) to obtain the fluid porosity. Regardless of which portion of Eq. A6 applies, $\square_{I}$ is linear in $\square_{\text {eff. }}$. The intersection between (A7) and a straight line: 


$$
\begin{aligned}
& \square_{I}=E \square_{\text {eff }}+F \ldots \ldots \ldots \ldots \ldots \ldots \ldots \ldots \ldots \ldots \ldots \ldots \\
& \square_{I}=\square_{*}+\sqrt{\square_{*}^{2} \square 4 \mathrm{FS} \square_{I} /\left(\square_{f} J\right)} \text { 目 } / 2 \ldots
\end{aligned}
$$

where

$$
\square_{*}=F+E\left(P_{m}+1 / \square_{f}\right)
$$

)

Back substitution into (A6) yields the effective mean stress.

Morris et al. ${ }^{8}$ obtained good agreement with experimentally measured permeabilities using

$$
k=k_{*} \exp \left\{K_{1} \square_{1}\left(\square_{\text {eff }}, D\right) \square D \min \left(D, D^{\max }\right)\right\}
$$

\section{Nomenclature}

$a=$ characteristic grain diameter (m)

$\mathrm{B}=$ Forchheimer coefficient $\left(\mathrm{m}^{-1}\right)$

$c_{1}, c_{2}=$ damage evolution constants

$C=$ incipient porosity reduction rate $\left(\mathrm{Pa}^{-1}\right)$

$D=$ damage factor

$D^{\max }=$ maximum damage factor

$E=$ incipient porosity increase rate $\left(\mathrm{Pa}^{-1}\right)$

$F=$ incipient porosity intercept

$J=$ ratio of specific volumes

$k=$ permeability $\left(\mathrm{m}^{2}\right)$

$k_{*}=$ initial permeability $\left(\mathrm{m}^{2}\right)$

$k_{o}=$ initial post-perforation permeability $\left(\mathrm{m}^{2}\right)$

$k_{\max }=$ maximum permeability after clean up $\left(\mathrm{m}^{2}\right)$

$K_{l}=$ permeability-porosity exponent

$P=$ pressure $(\mathrm{Pa})$

$\square P_{c r}=$ critical pressure gradient $(\mathrm{Pa} / \mathrm{m})$

$P_{p}=$ pore pressure $(\mathrm{Pa})$

$P_{m}=$ mean stress $(\mathrm{Pa})$
$P_{h 1}=$ minimum pressure for hydrostatic damage $(\mathrm{Pa})$

$P_{h 2}=$ maximum pressure for hydrostatic damage $(\mathrm{Pa})$

$P_{*}=$ critical effective pressure $(\mathrm{Pa})$

$P_{s}^{*}=$ maximum pressure-enhanced strain damage $(\mathrm{Pa})$

$r=$ radial dimension $(\mathrm{m})$

$S=$ saturation parameter

$t=$ time (s)

$u=\operatorname{mass}$ flux $\left(\mathrm{kg} / \mathrm{m}^{2} / \mathrm{s}\right)$

$v=$ fluid velocity $(\mathrm{m} / \mathrm{s})$

$x=$ axial dimension $(\mathrm{m})$

$\square x=$ grid spacing $(\mathrm{m})$

\section{Greek Symbols}

$\square_{f}=$ fluid compressibility $\left(\mathrm{Pa}^{-1}\right)$

$\square=$ plastic strain

$\square=$ porosity

$\square_{I}=$ incipient porosity

$\square_{I}^{o}=$ undamaged incipient porosity

$\square_{I}^{S}=$ incipient porosity for low-strain-rate (quasi-static) deformation

$\square_{I}^{D}=$ incipient porosity for high-strain-rate (dynamic) deformation

$\square *=$ incipient porosity intercept

$\square_{I}=$ reference incipient porosity

$\square=$ dynamic viscosity ( $\mathrm{Pa}-\mathrm{s})$

$\square=$ angular dimension

$\square=$ fluid density $\left(\mathrm{kg} / \mathrm{m}^{3}\right)$

$\square_{1}, \square_{2}, \square_{3}=$ priniciple stresses $(\mathrm{Pa})$

$\square_{\text {eff }}=$ effective stress $(\mathrm{Pa})$

$\square_{\text {eff }}^{\max }=$ maximum effective stress $(\mathrm{Pa})$

$\square_{\mathrm{t}}=$ tensile yield stress $(\mathrm{Pa})$

$\square_{\mathrm{o}}=$ tensile yield stress of undamaged rock $(\mathrm{Pa})$

$\square=$ trace of the deformation tensor 


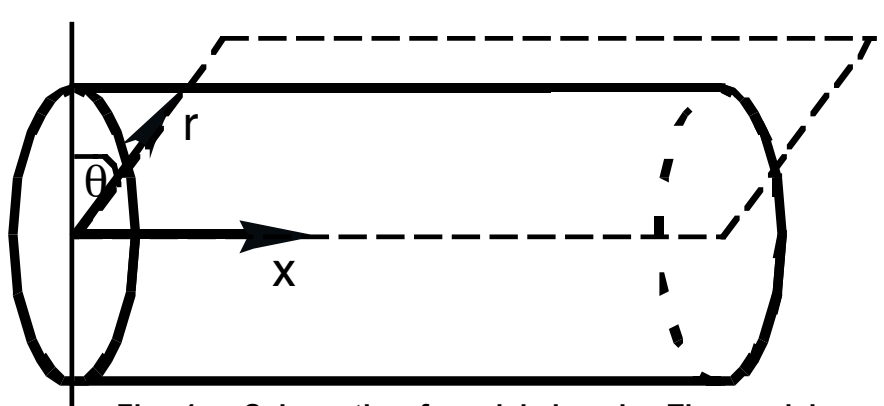

Fig. 1 _ Schematic of model domain. The model assumes radial symmetry, so simulations are carried out in the r-x plane.

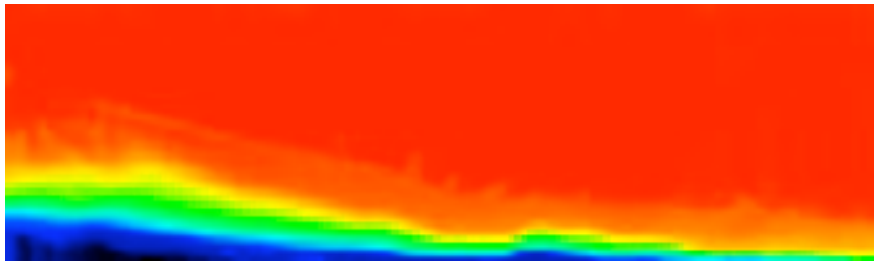

Fig. 2._Log-permeability distribution after jet penetration and prior to onset of post-perforation pressure surge in a 9-cm diameter, 19-cm long core. The color scale (blueyellow-red) represents increasing permeability
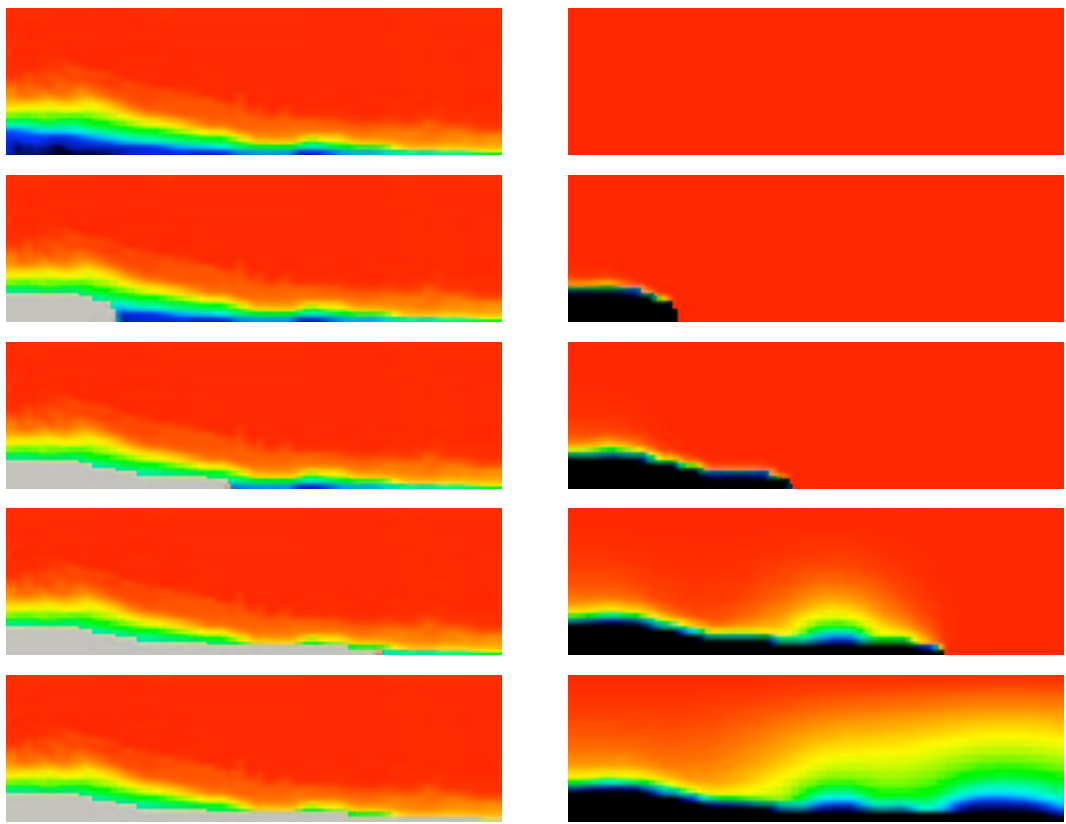

Fig. 3 _ Evolution of permeability in perforation tunnel (left) and pressure distribution (right) during post-perforation transient surge from reservoir to well bore (left edge of domain). Gray represents open perforation tunnel.

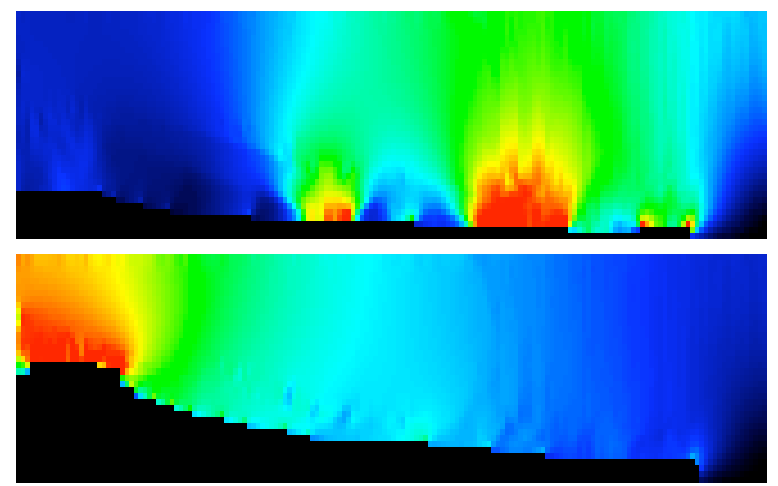

Fig. 4._ Mass flux around perforation tunnel at steady state for 750-psi underbalance (bottom) and 3000-psi underbalance (top). The color scale (red-yellow-blue) represents increasing mass flux 


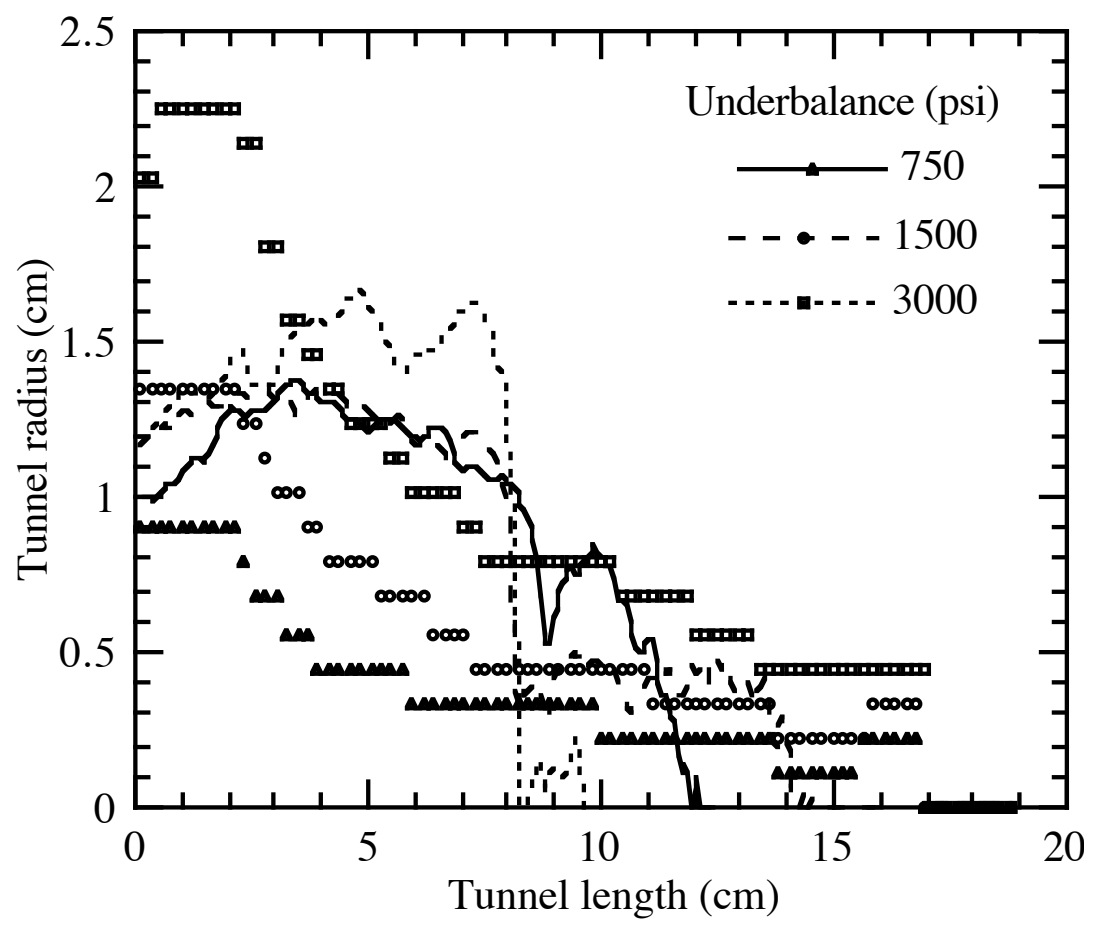

Fig. 5. _ Comparison of measured (solid lines) and simulated (data points) tunnel diameter along the tunnel length.

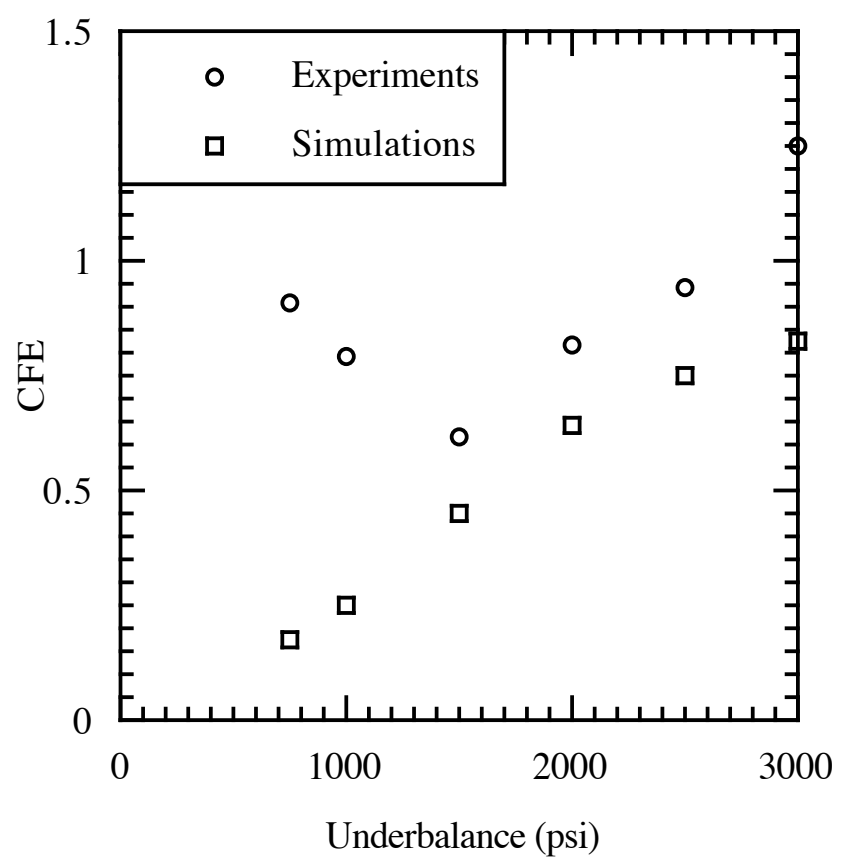

Fig. 6. _ Experimental and simulated CFEs for different underbalances 


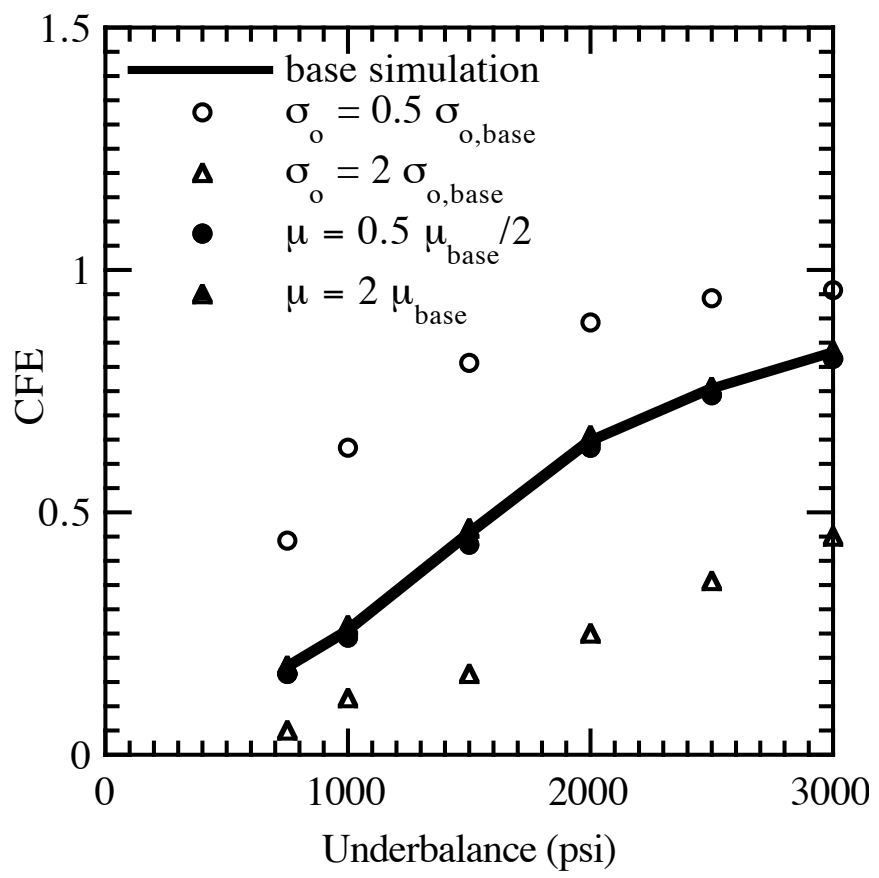

Fig. 7. Influence of fluid viscosity and rock tensile strength on calculated CFEs. 